\title{
HLA-DRB1 typing in rheumatoid arthritis: predicting response to specific treatments
}

\begin{abstract}
James R O'Dell, Barbara S Nepom, Claire Haire, Vivian H Gersuk, Lakshmi Gaur, Gerald F Moore, Walter Drymalski, William Palmer, P James Eckhoff, Lynell W Klassen, Steven Wees, Geoffrey Thiele, Gerald T Nepom
\end{abstract}

Department of
Internal Medicine,
University of Nebraska
Medical Center
(UNMC), USA
J R O'Dell
C Haire
G F Moore
L W Klassen

Omaha Veterans Affairs Medical

Center, USA

J R O'Dell

L W Klassen

\begin{abstract}
Objective-To determine the predictive value of shared epitope alleles for response to treatment in patients with rheumatoid arthritis.

Methods-Patients from our previously published triple DMARD study were tested for the presence of shared epitope alleles (DRB1 $\star_{0401,0404 / 0408,0405,0101,}$ 1001, and 1402). Patients who were shared epitope positive were then compared with those who were negative to see if there was a differential effect on therapeutic response.

Results-Shared epitope positive patients were much more likely to achieve a $50 \%$ response if treated with methotrexatesulphasalazine-hydroxychloroquine compared with methotrexate alone $(94 \%$ responders versus $32 \%, p<0.0001)$. In contrast shared epitope negative patients did equally well regardless of treatment $\mathbf{( 8 8 \%}$ responders for methotrexatesulphasalazine-hydroxychloroquine versus $83 \%$ for methotrexate). Additionally, a trend toward an inverse relation of the gene dose was seen for response to methotrexate treatment $(p=0.05)$.

Conclusions-These data suggest that determining shared epitope status may provide clinical information useful in selecting among treatment options. (Ann Rheum Dis 1998;57:209-213)
\end{abstract}

Rheumatoid arthritis (RA) is a chronic disease, with a spectrum of clinical manifestations characterised by synovial inflammation that leads to progressive joint damage, disability, and increased mortality. ${ }^{12}$ Conventional treatment for RA is essentially an empiric choice of disease modifying antirheumatic drugs (DMARDs) such as gold, hydroxychloroquine, sulphasalazine, d-penicillamine, azathioprine, and methotrexate; all these drugs have been shown to be effective individually, at least in the short-term..$^{3-5}$ Regrettably,with the exception of methotrexate, the long term efficacy of these drugs is less than ideal, so most patients are no longer taking them after two years because of toxicity or lack of efficacy. ${ }^{6} 7$ There is a need to identify additional therapeutic options that are both effective and well tolerated by individual patients. Various combination treatments in which multiple drugs are used simultaneously are under evaluation for improved clinical efficacy in an attempt to modulate the course of the disease more effectively in patients with severe clinical manifestations. We have recently reported on the superior efficacy of the combination of hydroxychloroquine, sulphasalazine, and methotrexate, as compared with methotrexate alone or hydroxychloroquine plus sulphasalazine in a double blind, randomised, controlled study, documenting clinical response over a two year treatment span. ${ }^{8}$ In that study, $77 \%$ of the patients treated with combination therapy had a marked clinical improvement, compared with $33 \%$ of the patients treated with methotrexate alone. The availability of successful combination treatments provides an impetus to start treatment earlier in the course of disease before severe manifestations occur. However, no standard assessment approach distinguishes patients likely to respond to monotherapy (for example, methotrexate) from those who are more suited to combination treatments.

Although the aetiology of RA is unknown, there is a strong genetic association between particular HLA-DR alleles and severe, progressive forms of the disease. In numerous studies of various populations, HLA-DRB1 alleles that contain a similar sequence at amino acid positions $67-74$ in the third hypervariable region of the DR molecule (called the "shared epitope") are associated with RA, including $\mathrm{DRB} 1{ }^{\star} 0401,{ }^{\star} 0404 /{ }^{\star} 0408,{ }^{\star} 0405,{ }^{\star} 0101$, $\star 1001$, and $\star 1402$ (reviewed in reference 9). In North American white people, the DRB ${ }^{\star} 0401$ and ${ }^{\star} 0404$ alleles are the most prevalent, and these genes are associated with the highest risk of severe disease. ${ }^{9-12}$

People with these alleles have an incidence of RA five times to seven times higher than people without these alleles; however, as these alleles are frequent in white populations, most people with these genes do not have RA, and the use of HLA typing for screening the general population for disease risk is therefore not practical. ${ }^{13}$ On the other hand, the presence of these alleles predisposing to severe, progressive disease potentially serves as a marker for poor prognosis of patients known to have RA. Within the spectrum of clinical manifestations, prediction of the disease's natural history and of the expected response to specific treatments may be improved by patient stratification for genetic and clinical markers indicating likelihood of severe, progressive disease.

Using patients from the clinical study mentioned above, we have now tackled the question of whether the response to treatment in patients with RA differs based on the presence of HLA-DRB1 alleles. 
Table 1 Baseline characteristics of patients, according to study group

\begin{tabular}{llll}
\hline Characteristic & $\begin{array}{l}\text { Methotrexate } \\
(n=28)\end{array}$ & $\begin{array}{l}\text { Sulphasalazine and } \\
\text { hydroxychloroquine } \\
(n=30)\end{array}$ & $\begin{array}{l}\text { All three drugs } \\
(n=26)\end{array}$ \\
\hline Age (y) & & & \\
$\quad$ mean & 50 & 49.8 & 50.4 \\
range & $26-69$ & $3-63$ & $27-67$ \\
Sex (F/M) & $18 / 10$ & $21 / 9$ & $16 / 10$ \\
Rheumatoid factor (\% positive) & 89 & 86 & 88 \\
DMARDs previously used & 1.5 & 1.5 & 1.4 \\
Current prednisone therapy (\%) & 54 & 47 & 50 \\
Shared epitope (\% positive) & 79 & 73 & 69 \\
\hline
\end{tabular}

\section{Methods}

GENERAL

The Rheumatoid Arthritis Investigational Network (RAIN) conducted this study in collaboration with the Virginia Mason Research Center. RAIN brings the rheumatologists at the University of Nebraska together with rheumatologists in Nebraska, Iowa, South Dakota, Minnesota, and Illinois who are interested in clinical studies in RA. All physicians who participate in this network not only are involved with patient enrollment and data collection, but also have aided in the development of the study protocols themselves.

\section{PATIENT SELECTION}

We asked patients who met criteria for this study to participate; they included those followed up in the rheumatology clinic at the University of Nebraska Medical Center, the Omaha Veterans Administration Medical Center, or in the private offices of network physicians. All patients enrolled signed an informed consent document approved by the Institutional Review Board.

Eligibility criteria for the original study as previously reported ${ }^{8}$ included active RA, previous treatment failure with at least one DMARD, and no previous treatment with combinations of the study drugs.

EXPERIMENTAL DESIGN

We enrolled 102 patients in the original two year, double blind, randomised, controlled study. The experimental design of the original study has been reported elsewhere. ${ }^{8}$ Briefly patients were randomised to one of three treatment groups: Group 1, methotrexate only; Group 2, hydroxychloroquine and sulphasalazine; Group 3, all three active compounds (table 1).

Patients were followed up by blinded evaluators until they completed the protocol (two years), until side effects occurred, or until they failed because of lack of efficacy. The major end point of our study was $50 \%$ improvement based on fulfilling three of the following requirements (modified Paulus ${ }^{14}$ ): (1) morning stiffness $<30$ minutes or improved by $50 \%$; (2) joint tenderness improved by $50 \%$; (3) joint swelling improved by $50 \%$; (4) sedimentation rates $<30 \mathrm{~mm} 1 \mathrm{st} \mathrm{h}$ for women or $<20 \mathrm{~mm}$ $1 \mathrm{st} \mathrm{h}$ for men. If patients did not meet these $50 \%$ improvement criteria at all of the three month evaluation periods after they had received maximal therapy (nine months), they were considered an efficacy failure. Using this end point, patients were classified as successful completers (50 patients) or efficacy failures (37 patients). An additional 13 patients were withdrawn because of medication side effects, and two patients did not complete because of protocol violations.

Blood was drawn for DNA analysis from 94 of 102 patients and included 86 of 87 patients $(99 \%)$ that could be analysed for efficacy (successful completers or efficacy failures). Because of the differences in frequency of the shared epitope among races, only white patients $(n=98)$ who were completers or who were efficacy failures were included in the subsequent analysis $(n=84)$. All DNA analysis was done by investigators blinded to the results of both the group assignment and the results of treatment.

\section{HLA-DRB1 ANALYSIS}

DNA was extracted from ficoll separated peripheral blood lymphocytes and amplified by the polymerase chain reaction. For determination of DR4 alleles, group specific biotinylated primers for DRA and DRB1*04 were used simultaneously. DR4 subtype was detected by subsequent hybridisation with allele specific oligonucleotide probes specific for the shared epitope region. ${ }^{15}$ Detection of the coamplified DRA gene served as an internal standard and was included as a technical control in each sample. Probes used for hybridisation were immobilised on a solid support, and presence of the amplified product was measured using streptavidin conjugated horseradish peroxidase, using a semi-automated GeneMAT ${ }_{\mathrm{RA}}$ DNA analysis system (Cypress Technologies). Other HLA alleles were determined by standard DNA based, non-radioactive methods. ${ }^{16}$

\section{STATISTICAL ANALYSIS}

The primary end point of the original study was successful completion of the two year protocol. Differences among the three treatment groups in completers and efficacy failures were analysed using both Fisher's exact test and the $\log$ rank test. ${ }^{17}$ In this study Fisher's exact test was used to compare the effects of shared epitope status in the three different treatment groups.

The differential effect of treatment group on the magnitude of the change in tender joint and swollen joint scores based on shared epitope status was also determined by the Fisher's exact test. The effect of gene dose on response to treatment was analysed by the analysis of variance.

\section{Results}

Eighty four white RA patients finished the two year study as either "successful completers" or "efficacy failures." Samples from these patients were tested for the presence of the RA associated alleles (shared epitope). Of these patients, $74 \%$ were positive for at least one shared epitope allele; while $29 \%$ were positive for some combination of two shared epitope alleles. These included $51 \%$ of patients positive for $\mathrm{DRB} 1^{\star} 0401$ (Dw4), $19 \%$ positive for ${ }^{\star} 0404 /{ }^{\star} 0408$ (Dw 14), $19 \%$ positive for ${ }^{\star} 0101(\mathrm{DR} 1), 5 \%$ positive for ${ }^{\star} 1001(\mathrm{DR} 10)$, and $5 \%$ positive for ${ }^{\star} 0405$ (Dw15). No ${ }^{\star} 1402$ 
Table 2 Effect of shared epitope on treatment response

\begin{tabular}{|c|c|c|c|c|c|c|c|c|c|}
\hline \multirow[b]{3}{*}{$\begin{array}{l}\text { Shared epitope } \\
\text { status }\end{array}$} & \multicolumn{6}{|c|}{ Treatment group } & \multirow{2}{*}{\multicolumn{3}{|c|}{$p$ Valuet }} \\
\hline & \multicolumn{2}{|c|}{ Methotrexate } & \multicolumn{2}{|c|}{ Sulphasalazine-hydroxychloroquine } & \multicolumn{2}{|c|}{ All three drugs } & & & \\
\hline & $\begin{array}{l}\text { Successful } \\
\text { completers }\end{array}$ & $\begin{array}{l}\text { Efficacy } \\
\text { failures }\end{array}$ & $\begin{array}{l}\text { Successful } \\
\text { completers }\end{array}$ & $\begin{array}{l}\text { Efficacy } \\
\text { failures }\end{array}$ & $\begin{array}{l}\text { Successful } \\
\text { completers }\end{array}$ & $\begin{array}{l}\text { Efficacy } \\
\text { failures }\end{array}$ & $\begin{array}{l}M T X v \\
\text { triple }\end{array}$ & $\begin{array}{l}\text { S and } H v \\
\text { triple }\end{array}$ & $\begin{array}{l}M T X v S \\
\text { and } H\end{array}$ \\
\hline Positive & $7(32 \%)$ & 15 & $10(45 \%)$ & 12 & $17(94 \%)$ & 1 & $<0.001$ & $<0.002$ & 0.35 \\
\hline Negative & $5(83 \%)$ & 1 & $3(38 \%)$ & 5 & $7(88 \%)$ & 1 & 0.69 & 0.06 & 0.09 \\
\hline $\mathrm{p}$ Value ${ }^{\star}$ & $<0.04$ & & 0.52 & & 0.53 & & & & \\
\hline
\end{tabular}

${ }^{\star} \mathrm{p}$ Value for comparisons of completers based on epitope status within each treatment group.

$\mathrm{tp}$ Value for comparison of treatment groups with the same epitope status.

(DR14) positive patients where found in this white population. The predictive value of these genes for response to treatment was assessed for patients receiving methotrexate alone, sulphasalazine-hydroxychloroquine, or all three drugs together.

As table 2 shows, the frequency of successful completion of the clinical trial showed marked differences among patients stratified by shared epitope status. Among patients receiving methotrexate alone, only $32 \%$ of the shared epitope positive patients successfully completed the study; on the other hand, $94 \%$ of shared epitope positive patients in the three drug group were successful completers $(p<0.001)$. The response of shared epitope positive patients treated with all three drugs was also significantly better than those treated with sulphasalazine-hydroxychloroquine (45\% response, $\mathrm{p}<0.002$ ).

Within the methotrexate treatment group, fewer shared epitope positive patients were successful completers compared with patients without the shared epitope $(p<0.04)$. This was not true for patients in the other treatment groups: fewer than half of the patients treated with sulphasalazine-hydroxychloroquine were successful completers, regardless of shared epitope status; whereas, most of the patients treated with all three drugs did well, regardless of shared epitope status.

Among shared epitope negative patients, those treated with all three drugs showed no difference in response rate from those treated with methotrexate alone (88\% versus $83 \%$ respectively, $\mathrm{p}=\mathrm{NS}$ ) but did respond better than those treated with sulphasalazine-

Table 3 Degree of clinical improvement stratified by shared epitope status

\begin{tabular}{|c|c|c|c|c|}
\hline Treatment group & $\begin{array}{l}\text { Shared } \\
\text { epitope } \\
\text { status }\end{array}$ & Change in tende & joints & Change in swollen joints \\
\hline Methotrexate & Negative & $-19.5(1.4)$ & \multirow{2}{*}{\} $\mathrm{p}=0.95$} & $-19.2(10.1)$ \\
\hline All three drugs & Negative & $-20.0(21.0)$ & & $-19.4(15.1)$ \\
\hline Methotrexate & Positive & $-12.5(14.7)$ & \multirow[b]{2}{*}{\} $\mathrm{p}=0.007$} & $-15.0(15.4)$ \\
\hline All three drugs & Positive & $-23.4(9.1)$ & & $-25.9(11.1)$ \\
\hline
\end{tabular}

Values are mean (SD) of the change in scores from start of treatment until study completion.

Table 4 Shared epitope dose effect: patients with 50\% response

\begin{tabular}{lllll}
\hline & $\begin{array}{l}\text { Double } \\
\text { dose }\end{array}$ & $\begin{array}{l}\text { Single } \\
\text { dose }\end{array}$ & None & p Value \\
\hline Methotrexate (\%) & $2 / 8(25)$ & $5 / 14(36)$ & $5 / 6(83)$ & 0.05 \\
Sulphasalazine-hydroxychloroquine (\%) & $4 / 8(50)$ & $6 / 14(43)$ & $3 / 8(38)$ & 1.0 \\
All three drugs (\%) & $5 / 5(100)$ & $12 / 13(92)$ & $7 / 8(88)$ & 1.0 \\
\hline
\end{tabular}

${ }^{\star} \mathrm{p}$ Values are for dose effect of each treatment. hydroxychloroquine ( $88 \%$ versus $38 \%$ respectively, $\mathrm{p}<0.02$ ).

To assure that these findings were not based in some way on the fact that we had in our original study chosen to define success as $50 \%$ improvement (rather than $20 \%, 60 \%$, or any other degree of improvement), we calculated the change in the tender and swollen joint scores (nine month scores minus initial scores) for patients based on treatment group and epitope status. As table 3 shows, shared epitope negative patients fared equally well regardless of whether they were treated with methotrexate or triple therapy. Shared epitope positive patients, however, improve much more if treated with triple therapy $(\mathrm{p}=0.007$ and $0.019)$.

The poor therapeutic response of the methotrexate treated shared epitope positive patients was further corroborated by analysis of the effect on dose of the shared epitope. As table 4 shows, there was a trend toward an inverse relation of gene dose on response to methotrexate $(p=0.05)$. This was not seen in the sulphasalazine-hydroxychloroquine group or in the group that received all three drugs.

The presence of rheumatoid factor, the duration of disease, and the number of DMARDs previously used were not predictive of response to treatment in this study.

\section{Discussion}

The choice of which of several available DMARDs to use in treating RA patients is an important dilemma faced by the rheumatologist. Currently, this is an empirical decision, and no laboratory or clinical assessments have predicted an individual patient's response to a particular drug or combination of drugs. There is a growing consensus that the earlier the appropriate treatment can be started, the better the outcome. ${ }^{318}$ DMARDs are generally slow acting, and joint damage progresses while the appropriate drug is sought.

Currently, methotrexate is the initial DMARD of choice for most rheumatologists. ${ }^{19}$ However, remissions are rare $^{2122}$ and only about $35 \%$ of methotrexate treated patients will meet $50 \%$ improvement criteria. ${ }^{8223} \mathrm{We}$ have recently demonstrated that the combination of methotrexate, sulphasalazine, and hydroxychloroquine is significantly more effective than methotrexate alone in treating patients with RA ( $77 \%$ versus $33 \%$ efficacy at two years using $50 \%$ improvement criteria). ${ }^{8}$ However, as some patients do well with methotrexate alone, the role of triple therapy in individual 
patients is unclear. A reliable predictor of response to specific treatments would greatly aid in the early application of appropriate therapy for RA.

Many studies have confirmed the strong association of particular HLA alleles with RA. ${ }^{24-27}$ The shared epitope, a sequence stretch in the third hypervariable region of the DRB1 molecule, has been most closely associated with this disease. ${ }^{28}{ }^{29}$ This sequence is found on several DR4 positive alleles $\left({ }^{\star} 0401,{ }^{\star} 0404\right.$, ${ }^{\star} 0405$, etc), as well as on some non-DR4 alleles $\left({ }^{\star} 0101,{ }^{\star} 1001\right.$, etc). Studies in white populations have generally agreed that the DR4 shared epitope positive alleles confer susceptibility for a more severe disease course, while alleles negative for the DR4 shared epitope are associated with milder disease. ${ }^{10}{ }^{11}$ 30-32 We chose to analyse shared epitope positive allele status among the patients who participated in a recent therapy trial, to determine whether this might predict response to specific treatment. Patients were typed using a DNA based, sequence specific, oligonucleotide probe assay for the alleles $\mathrm{DRB} 1{ }^{\star} 0401,{ }^{\star} 0404 /{ }^{\star} 0408$, ${ }^{\star} 0405,{ }^{\star} 0101,{ }^{\star} 1001$, and ${ }^{\star} 1402$ without knowledge of their treatment group or outcome.

A striking differential response to treatment in RA patients was observed, based on their shared epitope status. While most patients in the triple therapy arm of the study did well regardless of HLA type, those treated with methotrexate alone showed a marked difference; $83 \%$ of those patients who were shared epitope negative were successful completers, while only $32 \%$ of those who were shared epitope positive responded successfully. Looked at a different way, among patients positive for the shared epitope, $94 \%$ were successful completers if treated with triple therapy, but $68 \%$ were efficacy failures if treated with methotrexate alone. These results are consistent with reports that shared epitope positive patients are those at greatest risk for severe, erosive disease; it seems probable that such patients require more aggressive treatment to achieve a sustained clinical response. Similarly, patients negative for the shared epitope have been reported to have milder disease; these patients generally did well during the two year study period with methotrexate alone $(83 \%$ successful completers). Our results were similar if only DR4 associated share epitope positive patients were considered, which leaves open the question of whether non-DR4 associated alleles are important for prediction of response to treatment.

Joint inflammation multiplied by time equals increased joint damage in RA; thus, "time is cartilage," and earlier use of effective treatments is essential for optimum joint function and patient management. While many options are available when selecting DMARD therapy for patients with RA, it often takes one to six months before efficacy is seen, highlighting the importance of making therapeutic choices as soon as possible. As responses to any single DMARD differ among individual patient, many patients follow a disease course that may progress without sustained therapeutic response over several years, with resultant joint destruction. While predictive tools are necessarily imprecise, we are encouraged that the HLA markers studied in this report appear to be specific markers of response to treatment in a rigorous long term clinical trial protocol. Such genetic analysis may provide an assessment tool to aid in choosing early treatment for patients with RA, thereby helping to prevent or delay some of the morbidity and mortality associated with this disease.

Taken together, these findings suggest the design of specific protocols using genetic markers in conjunction with aggressive therapeutics. These data, if they can be confirmed in other patient populations, suggest that typing RA patients to determine shared epitope status may be clinically useful. Larger studies to confirm these findings in other study populations are currently underway.

We are indebted to Ms Reneé Crosby for assistance in the preparation of the manuscript; to Michael Duryee for DNA preparation; to $\mathrm{Mr}$ David Nicklin for expert review of the manuscript; to Muriel Block, RN, and Rayla Otto, PA for assistmanuscript; to Muriel Block, RN, and Rayla Otto, PA for assistdispensing the study medications; to Kash Patil, PhD for statisdispensing the study medications; to Kash Patil, PhD for statis-

This work was supported in part by grants from the Dodson Foundation and the Hansen Foundation.

1 Pincus T, Brooks RH, Callahan LF. Prediction of long-term mortality in patients with rheumatoid arthritis according to simple questionnaire and joint count measures. Ann Intern Med 1994;120:26-34.

2 Wolfe F, Mitchell DM, Sibley JT, Fries JF, Bloch DA, Wolfe $\mathrm{F}$, Mitchell DM, Sibley JT, Fries JF, Bloch DA,
Williams CA, et al. The mortality of rheumatoid arthritis. Williams CA, et al. The mortality

3 American College of Rheumatology Ad Hoc Committee on Clinical Guidelines. Guidelines for the management of rheumatoid arthritis. Arthritis Rheum 1996;39:713-22

4 Felson DT, Anderson JJ, Meenan RF. The comparative efficacy and toxicity of second-line drugs in rheumatoid arthritis. Results of two metaanalyses. Arthritis Rheum 1990;33:1449-61.

5 Felson DT, Anderson JJ, Meenan RF. Use of short-term efficacy/toxicity tradeoffs to select second-line drugs in rheumatoid arthritis. A metaanalysis of published clinical trials. Arthritis Rheum 1992;35:1117-25.

6 Wolfe F, Hawley DJ, Cathey MA. Termination of a slow acting antirheumatic therapy in rheumatoid arthritis: a Rheumatol 1990;17:994-1002.

7 Morand EF, McCloud PI, Littlejohn GO. Life table analysis of 879 treatment episodes with slow acting antirheumatic drugs in community rheumatology practice. J Rheumatol 1992;19:704-8

8 O'Dell JR, Haire CE, Erickson N, Drymalski W, Palmer W, Eckhoff PJ, et al. Treatment of rheumatoid arthritis with methotrexate, sulfasalazine, and hydroxychloroquine, or a combination of these medications. N Engl J Med 1996;334:1287-91.

9 Nepom GT. HLA-DR4 and rheumatoid arthritis. In: Wolfe $\mathrm{F}$, Pincus $\mathrm{T}$, eds. Prognosis and treatment of rheumatic diseases. New York: Marcel Dekker, 1994: 115-29.

10 Weyand CM, Hicok KC, Conn DL, Goronzy JJ. The influence of HLA-DRB1 genes on disease severity in rheumatoid arthritis. Ann Intern Med 1992;1 17:801-6.

11 MacGregor A, Ollier W, Thomson W, Jawaheer D, Silman A. HLA-DRB1 ${ }^{\star} 0401 / 0404$ genotype and rheumatoid arthritis: Increased association in men, young age at onset, and disease severity. J Rheumatol 1995;22:1032-6.

12 Emery P, Salmon M, Bradley H, Wordsworth P, Tunn E, Bacon PA, et al. Genetically determined factors as predictors of radiological change in patients with early symmetrical arthritis. BMJ 1992;305:1387-9.

13 Nepom GT, Nepom BS. Prediction of susceptibility to rheumatoid arthritis by human leukocyte antigen genotyping. In: Nepom GT, ed. Rheumatic disease clinics of North America. Philadelphia: WB Saunders Company, 1992:78592.

14 Paulus HE, Egger MJ, Ward JR, Williams HJ, and the Cooperative Systematic Studies of the Rheumatic Diseases Group. Analysis of improvement in individual rheumatoid arthritis patients treated with disease-modifying antirheumatic drugs, based on the findings in patients treated with placebo. Arthritis Rheum 1990;33:477-84.

15 Nepom GT, Gersuk V, Nepom BS. Prognostic implications of HLA genotyping in the early assessment of patients with rheumatoid arthritis. J Rheumatol 1996;23 (suppl 44):5-9. 
16 Leech NJ, Kitabchi AE, Gaur LK, Hagopian WA, Hansen J, Burghen GA, et al. Genetic and immunological markers of insulin dependent diabetes in black americans. Autoimmunity $1995 ; 22: 27-32$.

17 Zar JH. Biostatistical analysis. 2nd ed. Englewood Cliffs, NJ: Prentice-Hall, 1984.

18 Kremer JM. The changing face of therapy for rheumatoid arthritis. Rheumatic Disease Clinics $1995 ; 21.3: 845-52$.

19 O'Dell JR. The treatment of rheumatoid arthritis in 1995 : Results of a survey. Arthritis Rheum 1995;38:S366.

20 Wolfe F, Hawley DJ. Remission in rheumatoid arthritis. J Rheumatol 1985;12:245-52.

21 Alarcon GS, Blackburn WD Jr, Calvo A, Castaneda O Evaluation of the American Rheumatism Association Preliminary Criteria for Remission in rheumatoid arthritis: a prospective study. J Rheumatol 1987;14:93-6.

22 Weinblatt ME. Methotrexate (MTX) in rheumatoid arthritis (RA): a 5-year multicenter prospective trial: Arthritis Rheum 1993;36:S79.

23 Kremer JM, Lee JK. A long-term prospective study of the use of methotrexate in rheumatoid arthritis. Arthritis Rheum 1988;31:577-84.

24 McMichael SJ, Sasazuki T, McDevitt HO, Payne RO. Increased frequency of HLA-Cw3 and HLA-Dw 4 in rheuIncreased frequency of HLA-Cw3 and HLA-Dw4 in r
matoid arthritis. Arthritis Rheum 1977;20:1037-42.

25 Stastny P. Association of the B-cell alloantigen DRw4 with rheumatoid arthritis. N Engl J Med 1978;298:869-71.
26 Nepom GT, Byers P, Seyfried C, Healey LA, Wilske KR, Stage $\mathrm{D}$, et al. HLA genes associated with rheumatoid Stage D, et al. HLA genes associated with
arthritis. Arthritis Rheum 1989;32:15-21.

27 Wordsworth B, Lanchbury JSS, Sakkas LI, Welsh KI, Panayi GS, Bell JI. HLA-DR4 subtype frequencies in rheumatoid
arthritis indicate that DRB1 is the major susceptibility arthritis indicate that DRBI is the major susceptibility locus within the HLA clas
USA $1989 ; 86: 10049-53$.

28 Gregersen PK, Silver J, Winchester RJ. The shared epitope hypothesis: An approach to understanding the molecular genetics of susceptibility to rheumatoid arthritis. Arthritis Rheum 1987;30:1205-13.

29 Winchester R, Dwyer E, Rose S. The genetic basis of rheumatoid arthritis: The shared epitope hypothesis. In: Nepom GT, ed. Rheumatic disease clinics of North America. Philadelphia: WB Saunders Company, 1992:761-83.

30 Young A, Jaraquemada D, Awad J, Festenstein H, Corbett $\mathrm{M}$, Hay FC, et al. Association of HLA-DR4/Dw4 and DR2/Dw2 with radiologic changes in a prospective study of DR2/Dw2 with radiologic changes in a prospective study of
patients with rheumatoid arthritis. Arthritis Rheum 1984; patients with

31 McMahon MJ, Hillarby MC, Clarkson RWE, Hollis S, Grennan DM. Major histocompatibility complex variants and articular disease severity in rheumatoid arthritis. Br J

32 Combe B, Eliaou J-F, Daures J-P, Meyer O, Clot J, Sany J. Prognostic factors in rheumatoid arthritis. Comparative study of two subsets of patients according to severity of articular damage. Br J Rheumatol 1995;34:529-34.

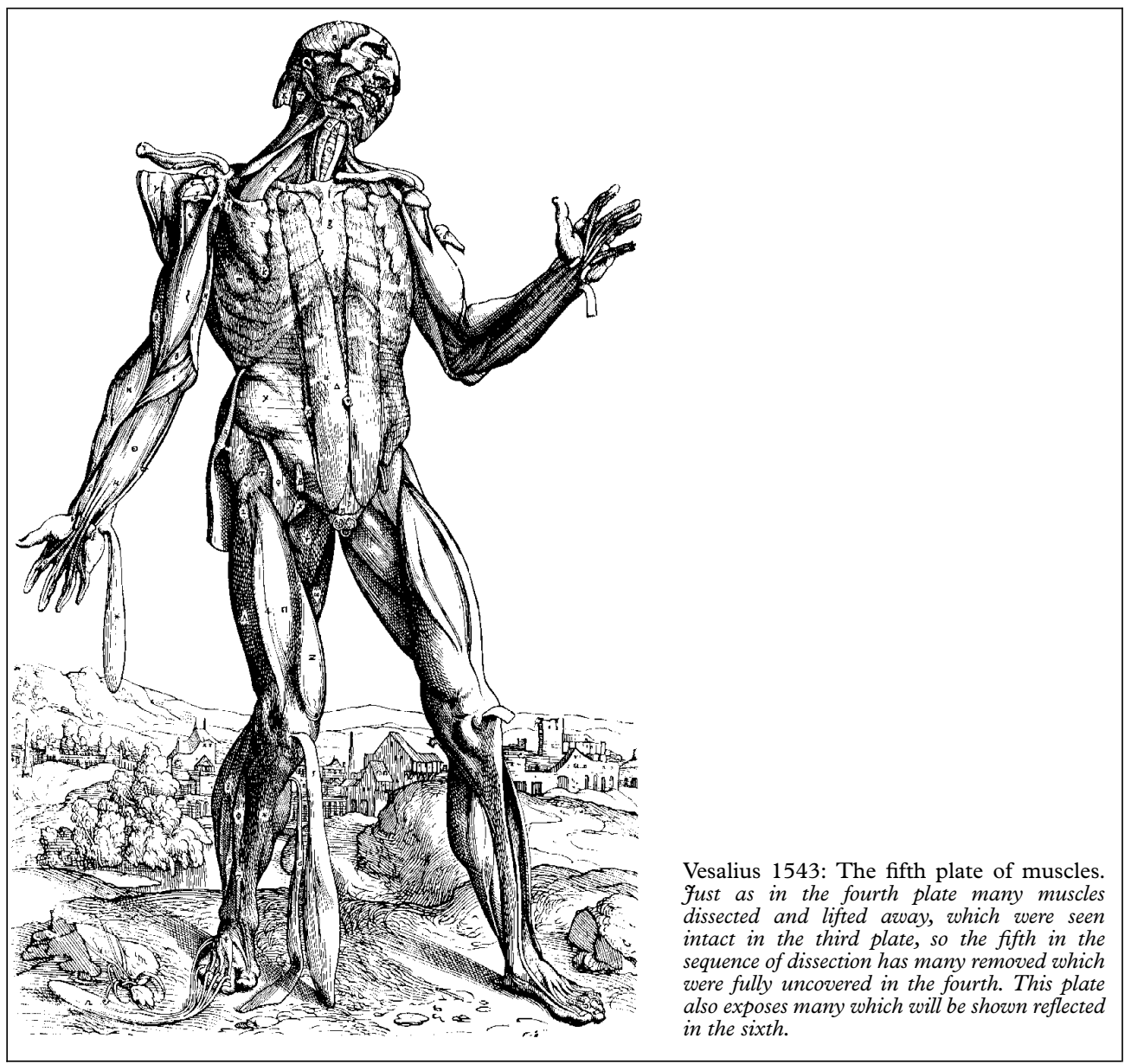

